\title{
Asymmetric catalytic synthesis of polyketones and polycarbonates*
}

\author{
Kyoko Nozaki \\ Department of Chemistry and Biotechnology, Graduate School of Engineering, \\ The University of Tokyo, 7-3-1 Hongo, Bunkyo-ku, Tokyo 113-8656, Japan
}

\begin{abstract}
Two examples are presented for the synthesis of optically active polymers with main-chain chirality from achiral monomers using chiral metal-complexes as catalysts. Asymmetric alternating copolymerization of $\alpha$-olefins with carbon monoxide provided optically active polyketones when catalyzed by an $(R, S)$-BINAPHOS-Pd complex. From propene and $\mathrm{CO}$, highly isotactic polyketone with high enantioselectivity ( $>97 \%$ like diad and $>95 \%$ ee). Spectroscopic and theoretical studies revealed that the olefin insertion is the key step for the enantiofacial selection and that this step takes place at cis to the phosphine part of $(R, S)$-BINAPHOS. The catalyst is applicable not only to propene/CO but also to styrene/CO, which enabled the first asymmetric terpolymerization of propene/styrene/CO. The catalyst tolerates funational groups such as fluorocarbons and a nitrile group so that they can be incorporated in the side chain. Optically active polycarbonate was also synthesized by the alternating copolymerization of cyclohexene oxide with carbon dioxide via the desymmetrization of the meso-epoxide. Dinuclei zinc species prepared from diethylzinc, ethanol, and $\alpha, \alpha^{\prime}$-diphenylprolinol, was revealed to be the real active species.
\end{abstract}

\section{INTRODUCTION}

$\mathrm{C}_{1}$ resources such as carbon monoxide, carbon dioxide, methane, and methanol have been considered to be attractive raw materials for the chemical industry, as alternative to unrecoverable fossil resources, especially petroleum. Use of $\mathrm{CO}$ in combination with transition-metal catalysts has recently made great advances in the manufacturing of industrial chemicals [1]. Since early 1990s, we have been engaged in the development of fine-chemical processes, especially asymmetric catalysis, utilizing CO. In 1993, we reported a striking improvement in the enantioselectivity of asymmetric hydroformylation using a rhodium complex of a chiral phosphine-phosphite $(R, S)$-BINAPHOS, an unsymmetrical bidentate ligand [2]. Several classes of alkenes, such as arylalkenes, conjugated dienes, and hetero-atom functionalized alkenes, were converted into their corresponding chiral aldehydes mostly over $90 \%$ ee. Even after one decade since its first discovery, the catalyst still keeps the highest regio- and enantioselectivities among other examples [3]. The unique feature of the ligand is its two nonequivalent phosphorus atoms, which enabled the exclusive apical-equatorial coordination to the trigonal bipyramidal rhodium center producing a single active species. With this unique ligand in hand, we examined another type of asymmetric carbonylation of olefins, the alternating copolymerization of $\alpha$-olefins with CO. Optically active polyketones with main-chain chirality could be thus produced from achiral monomers. As another example of asymmetric polymerization of achiral monomers, here we present the asymmetric al-

\footnotetext{
*Plenary and invited lectures presented at the $12^{\text {th }}$ IUPAC International Symposium on Organometallic Chemistry Directed Towards Organic Synthesis (OMCOS-12), Toronto, Ontario, Canada, 6-10 July 2003. Other presentations are published in this issue, pp. 453-695.
} 
Hydroformylation

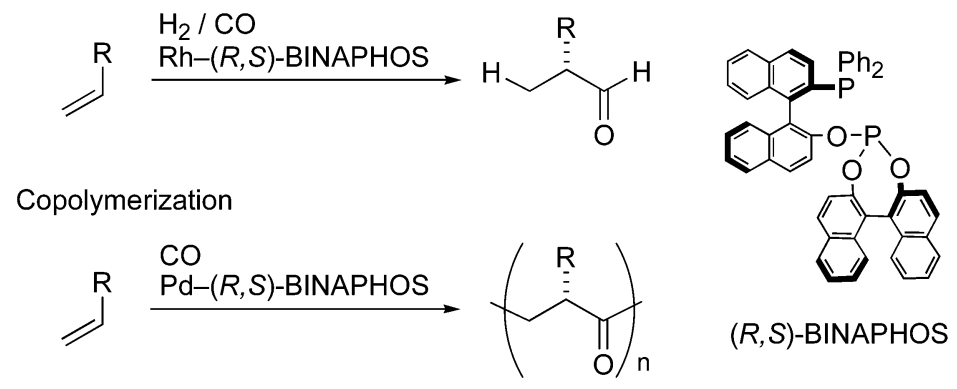

Fig. 1 Highly selective asymmetric carbonylation of olefins.

ternating copolymerization of meso-epoxide with carbon dioxide to afford optically active aliphatic polycarbonates.

\section{ASYMMETRIC SYNTHESIS OF POLYKETONES}

\section{Selectivities to be controlled in the alternating copolymerization of olefins with carbon monoxide}

The copolymerization of ethene with $\mathrm{CO}$ using transition-metal catalysts provides the perfectly alternating copolymer, poly(1-oxo-trimethylene) [4]. When a 1-alkene such as propene or styrene is used in place of ethene, three more factors must be controlled for obtaining stereoregular alternating copolymers (Fig. 2). (1) Regioselectivity: depending on the insertion direction of $\alpha$-olefin, there are three kinds of possible unit structures, namely, head-to-tail, head-to-head, and tail-to-tail. When all the monomers insert with the same regioselectivity, the resulting polymer consists of a head-to-tail structure. (2) Tacticity: the head-to-tail copolymer possesses asymmetric centers in the main-chain. Two kinds of tacticity are drawn in Fig. 2; the syndiotactic copolymer consists of the alternating order of the absolute configuration, RSRS-, while isotactic copolymer contains the same absolute configuration order either $R R R R$ - or $S S S S$ - . (3) Enantioselectivity: Two enantiomers exist for the isotactic copolymer, RRRR - and SSSS - . We examined the catalytic asymmetric synthesis of the isotactic copolymer.

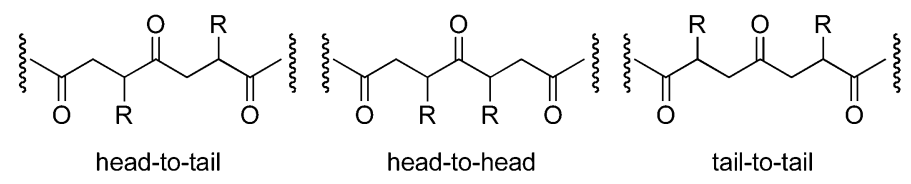

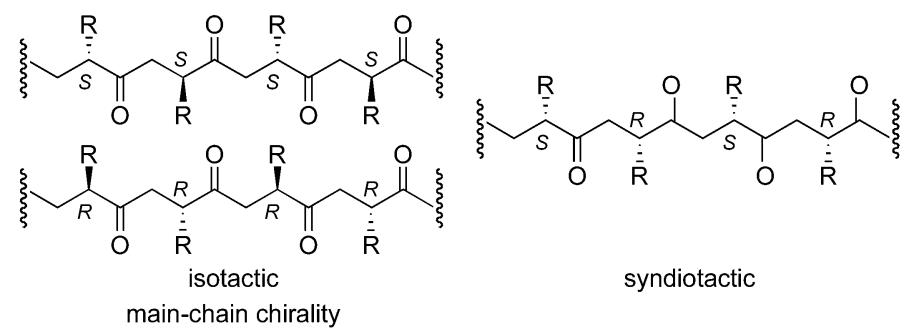

Fig. 2 Selectivities to be controlled in the alternating $\alpha$-olefins/CO copolymerization. 


\section{Asymmetric alternating copolymerization of propene with carbon monoxide}

The first example of the alternating copolymerization of propene with carbon monoxide was reported in the patent from Shell in 1985 using $\mathrm{L}_{2} \mathrm{PdX}_{2}\left(\mathrm{~L}_{2}=\right.$ bidentate phosphine such as dppp, $\mathrm{X}=$ a weakly or noncoordinating anion) as a catalyst [4]. Consiglio improved the head-to-tail selectivity to $>99 \%$ using a bis(trialkylphosphine), dippp [1,3-bis(diisopropylphosphino)propane], in place of dppp [5]. Chiral ligand was first employed for copolymerization of propene with carbon monoxide by Wong in 1990 [6]. The polymer which showed a specific rotation of $[\alpha]_{D}^{25}+10.4$ (in HFIP) was obtained using a chiral bisphosphine ligand, (-)-4,5-bis(dibutylphosphinomethyl)-2,2-dimethyl-1,3-dioxolane (1) (Scheme 1). In 1992, the first successful example of asymmetric copolymerization was reported by Consiglio, using chiral bis(dialkylmonoarylphosphine) with axial asymmetry, BICHEP (2), as a ligand [7]. With the ligand, a stereoregularity of the polyketone is $100 \%$ of head-to-tail structure and $93 \%$ of like-diad, exhibiting a high degree of $[\alpha]^{20}{ }_{\mathrm{D}}+26$ (in HFIP) and $\varepsilon=+1.56$ (in HFIP). In 1995, Sen reported that completely head-to-tail and isotactic copolymer was obtained by the use of chiral bis(dialkylmonoarylphosphine), (S,S)-Me-DUPHOS (3) [8]. Also, in 1995, we achieved the synthesis of the polyketone using chiral phosphine-phosphite ligand, $(R, S)$-BINAPHOS $(4)$, the polymer showing the highest molecular weight of $\mathrm{Mn}=65300$ and molar rotation of $[\Phi]^{24}{ }_{\mathrm{D}}-40(c 0.51$ in HFIP) [9]. The polyketone obtained by $\left[\mathrm{Pd}\{(R, S)\right.$-BINAPHOS $\left.\}(\mathrm{Me})\left(\mathrm{CH}_{3} \mathrm{CN}\right)\right]\left[\mathrm{B}\left\{3,5-\left(\mathrm{CF}_{3}\right)_{2} \mathrm{C}_{6} \mathrm{H}_{3}\right\}_{4}\right]$ system was perfectly isotactic polymer. Very recently, another example of unsymmetrical bidentate ligand $\mathbf{5}$ was reported to be an efficient catalyst for the asymmetric propene/CO copolymerization [10].

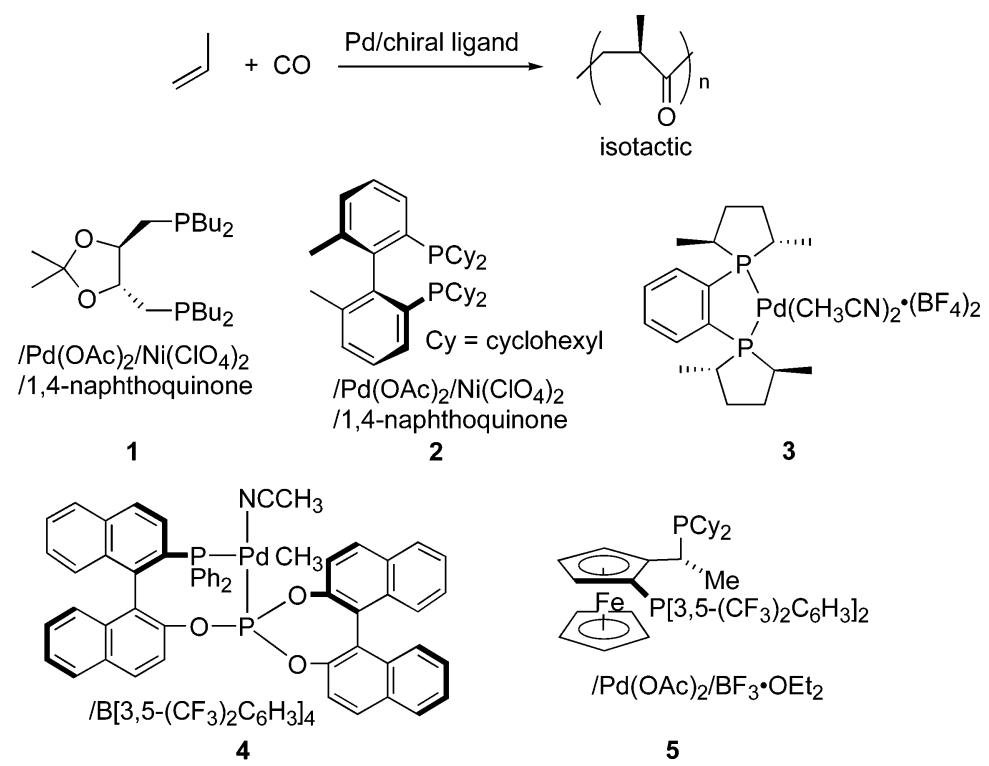

Scheme 1 Asymmetric alternating copolymerization of propene with CO.

Sen reported that the degree of the enantioselectivity of absolute configuration of asymmetric carbon was found to be $>90 \%$ by the ${ }^{13} \mathrm{C}$ NMR observation of carbonyl carbon in the presence of chiral NMR shift reagent [8]. Consiglio showed that a head-to-tail dimer, anti-dimethyl 4-oxodimethylheptanedioate, was obtained in $85 \%$ selectivity over other diastereomers with $>98 \%$ ee using 2, when the shorter oligomers were produced by adding a large amount of an oxidant (Scheme 2, above) [11]. Nozaki demonstrated that the absolute configuration of the polyketone produced by $\mathrm{Pd}-(R, S)$-BINAPHOS system is $S$, by the preparation of a model compound, methyl (S)-3-methyl-4-oxo-pentanoate, obtained in the initiation reaction of polymerization (Scheme 2, below) 


$$
+\mathrm{CO} \stackrel{\substack{\mathrm{Pd}\left[\left(\mathrm{H}_{2} \mathrm{O}\right)_{2}(\mathbf{2})\right](\mathrm{OTf})_{2} \\ 1,4 \text {-benzoquinone (excess) }}}{[}
$$

Scheme 2 Model studies to determine the enantioselectivity of the copolymerization.

[9]. The degree of enantiomeric excess of the model compound is $95 \%$, which indicates that the absolute configuration of asymmetric carbon in the polymer main-chain is perfectly controlled to be $S$. Also $(S)$-polyketone showed the positive optical rotation in HFIP and negative in $\mathrm{CHCl}_{3}$.

\section{Asymmetric alternating copolymerization of vinylarene with carbon monoxide}

Aryl-substituted alkenes, such as styrene and its analogs, show different polymerization behavior from the aliphatic 1-alkenes described above. Perfectly alternating copolymer with over $90 \%$ syndiotactic diad is given from styrene and $\mathrm{CO}$ when a bidentate nitrogen ligand, such as $2,2^{\prime}$-bipyridine or 1,10-phenanthroline is employed. Brookhart first reported the asymmetric alternating copolymerization of 4-tert-Bu-styrene with carbon monoxide using a chiral bisoxazoline ligand $\mathbf{6}$ to give completely isotactic copolymer (Scheme 3) [12]. Except for 4 [9], bidentate $\mathrm{sp}^{2}$-nitrogen ligands are mostly used for the reaction rather than bisphosphines.

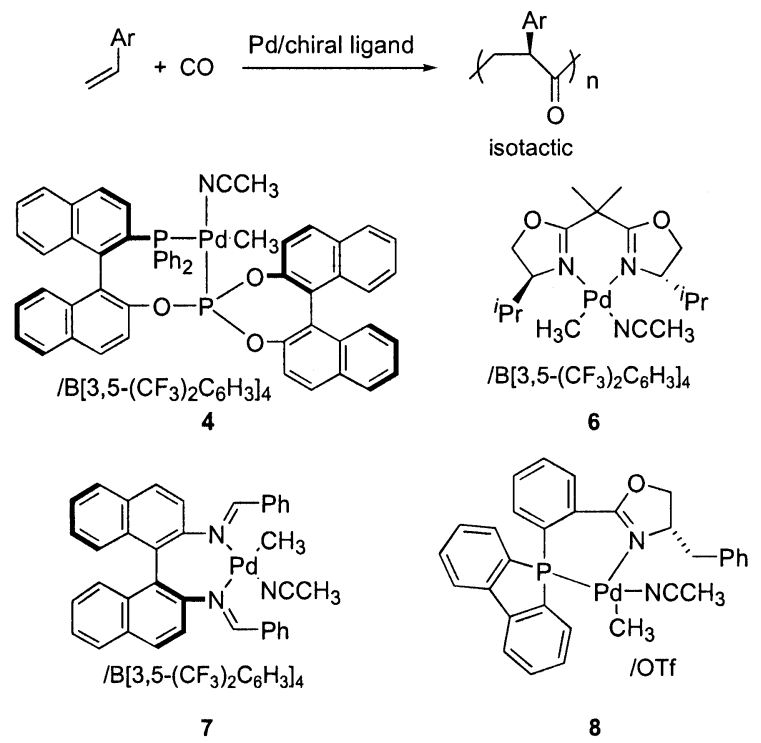

Scheme 3 Asymmetric alternating copolymerization of vinylarene with CO. 


\section{ASYMMETRIC SYNTHESIS OF POLYCARBONATES}

The utilization of carbon dioxide as a feedstock for organic compounds receives worldwide interest. One of the most promising processes for $\mathrm{CO}_{2}$ utilization is the alternating copolymerization of epoxide and carbon dioxide to yield aliphatic polycarbonate [13]. In 1969, Inoue first reported the synthesis of high-molecular-weight poly(propylene carbonate) by the alternating copolymerization of propene oxide and carbon dioxide using $\mathrm{Et}_{2} \mathrm{Zn} /$ water mixture as a catalyst [14]. An accepted reaction mechanism for the copolymerization of epoxide and carbon dioxide is (i) $\mathrm{CO}_{2}$ insertion into $\mathrm{Zn}$-alkoxide bond to form zinc carbonate, and (ii) the ring-opening of epoxide by the back-side attack of the resulting carbonate anion [15]. Thus, if the ring-opening copolymerization of meso-epoxide with $\mathrm{CO}_{2}$ takes place via the configuration inversion at one of the two chirotopic centers selectively, optically active aliphatic polycarbonate consists of either $(R, R)$ - or $(S, S)$-trans-1,2-diol unit should be produced [16]. In 1999, we reported the first example of the asymmetric alternating copolymerization of meso-epoxide with $\mathrm{CO}_{2}$ [17]. Optically active poly [cyclohexene oxide-alt $-\mathrm{CO}_{2}$ ] was obtained by using an equimolar mixture of $\mathrm{Et}_{2} \mathrm{Zn}$ and $(S)$-diphenyl(pyrrolidin-2-yl)methanol (9) as a chiral catalyst (Scheme 4). Because polycarbonate can be hydrolyzed into trans-1,2-diol and $\mathrm{CO}_{2}$ by alkali-treatment, the degree of asymmetric induction, $70 \%$ ee, could be evaluated unambiguously. In 2000, Coates reported the asymmetric alternating copolymerization using a well-defined $\mathrm{Zn}$-imine oxazoline ligand complex 10, which showed higher activity and controlled molecular weight compared to 9 [18]. More recently, we reported the improved enantioselectivity of $80 \%$ by using dimeric zinc complex 11 in which one of the two zinc atoms is attached to an ethoxy group while the other is to an ethyl group [19]. The copolymer obtained with 11 has EtOCOO- end group, indicating that the initiation reaction occurred by the insertion of $\mathrm{CO}_{2}$ into the $\mathrm{Zn}$-OEt bond. In spite of its high stereoregularity, the copolymer of $80 \%$ ee shows glass-transition temperature at $117{ }^{\circ} \mathrm{C}$, the value being very close to the ones previously reported for the copolymers with lower stereoregularity.
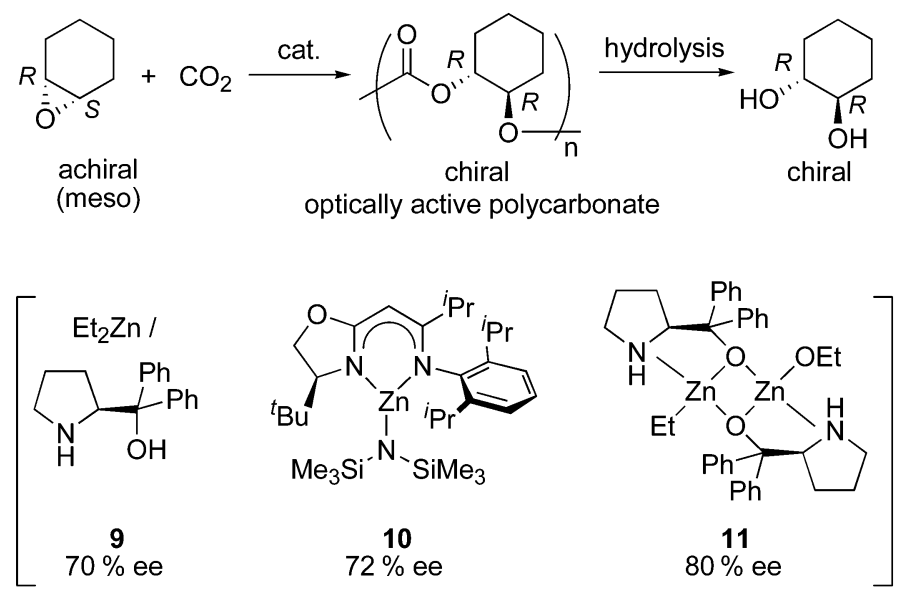

Scheme 4 Asymmetric alternating copolymerization of cyclohexene oxide with $\mathrm{CO}_{2}$.

\section{CONCLUSION}

Needless to say, the potential utility of polymers depend on the functional groups included in the polymers. At the same time, the solid-state arrangement of the polymer chains also significantly affects their properties. As was evidenced in this review article, single-site metal complexes enabled to produce polymers of different stereoregularity, even if the polymerization employ the same monomer(s). The different stereoregularity may induce difference in physical property. 
Asymmetric synthesis of chiral polymers from achiral monomers is now achieved for several polymers. The content of each enantiomer is essential to control the stereocomplex formation. In addition, here we propose another viewpoint of chirality: when we consider that our product plastics are used in our environment, we cannot avoid thinking about how it affects the nature. Because Mother Nature is chiral, enantiomeric polymers should be considered as different a product from each other, as is so in pharmacology.

\section{REFERENCES}

1. B. Cornils and W. A. Herrmann (Eds.). Applied Homogeneous Catalysis with Organometallic Compounds, VCH, Weinheim (1996).

2. N. Sakai, S. Mano, K. Nozaki, H. Takaya. J. Am. Chem. Soc. 115, 7033-7034 (1993).

3. (a) K. Nozaki and I. Ojima. In Catalytic Asymmetric Synthesis, $2^{\text {nd }}$ ed., I. Ojima (Ed.), Chap. 7 , John Wiley, New York (2000); (b) K. Nozaki. In Comprehensive Asymmetric Catalysis, Vol. I, E. Jacobsen, A. Pfaltz, H. Yamamoto (Eds.), Chap. 11, Springer, Berlin (1999); (c) K. Nozaki, H. Takaya, T. Hiyama. Top. Catal. 4, 175-185 (1997).

4. (a) E. Drent and P. H. M. Budzelaar. Chem. Rev. 96, 663 (1996); (b) A. Sen (Ed.). Catalytic Synthesis of Alternating Alkene-Carbon Monoxide Copolymers, Kluwer, Amsterdam (2003).

5. A. Batstini, G. Consiglio, U. W. Suter. Angew. Chem., Int. Ed. Engl. 31, 303 (1992).

6. P. K. Wong. Eur. Pat. Appl. 384, 517 (1990).

7. (a) A. Batistini and G. Consiglio. Organometallics 11, 1766 (1992); (b) S. Bronco, G. Consiglio, R. Hutter, A. Batistini, U. W. Suter. Macromolecules 27, 4436 (1994); (c) S. Bronco and G. Consiglio. Macromol. Chem. Phys. 197, 355 (1996).

8. Z. Jiang and A. Sen. J. Am. Chem. Soc. 117, 4455 (1995).

9. (a) K. Nozaki, N. Sato, H. Takaya. J. Am. Chem. Soc. 117, 9911 (1995); (b) K. Nozaki, N. Sato, Y. Tonomura, M. Yasutomi, H. Takaya, T. Hiyama, T. Matsubara, N. Koga. J. Am. Chem. Soc. 119, 12779 (1997); (c) K. Nozaki and T. Hiyama. J. Organomet. Chem. 576, 248 (1999).

10. (a) S. Bronco, G. Consiglio, S. Di Benedetto, M. Fehr, F. Spindler, A. Togni. Helv. Chim. Acta. 78, 883 (1995); (b) C. Gambs, S. Chaloupka, G. Consiglio, A. Togni. Angew. Chem., Int. Ed. Engl. 39, 2486 (2000); (c) C. Gambs, G. Consiglio, A. Togni. Helv. Chim. Acta. 84, 3105 (2001).

11. M. Sperrle and G. Consiglio. J. Am. Chem. Soc. 117, 12130 (1995).

12. M. Brookhart and M. I. Wagner. J. Am. Chem. Soc. 116, 3641 (1994).

13. (a) A. Rokicki and W. Kuran. J. Macromol. Sci., Rev. Macromol. Chem. C21, 135 (1981); (b) S. Inoue. In Carbon Dioxide as a Source of Carbon, M. Aresta (Ed.), p. 331, Reidel, Dordrecht (1987); (c) D. J. Darensbourg and M. W. Holtcamp. Coord. Chem. Rev. 153, 155 (1996).

14. S. Inoue, H. Koinuma, T. Tsuruta. J. Polym. Sci., Part B. 7, 287 (1969).

15. Z. Liu, M. Torrent, K. Morokuma. Organometallics 21, 1056 (2002).

16. S. Inoue, H. Koinuma, Y. Yokoo, T. Tsuruta. Makromol. Chem. 143, 97 (1971).

17. K. Nozaki, K. Nakano, T. Hiyama. J. Am. Chem. Soc. 121, 11008 (1999).

18. M. Cheng, N. A. Darling, E. B. Lobkovsky, G. W. Coates. Chem. Commun. 2007 (2000).

19. K. Nakano, K. Nozaki, T. Hiyama. J. Am. Chem. Soc. 125, 5501 (2003). 